\title{
Correlation Between Video-Otoendoscopy and Tympanograms of Patients with Acute Middle Ear Infections
}

\author{
Mohd. Aftab ${ }^{1} \cdot$ Sachin Jain $^{1} \cdot$ Ridhima Malik $^{1}(1) \cdot$ Pramod Kumar $^{1}$ • \\ Rajendra Kumar Gola ${ }^{1} \cdot$ Sachin Singh $^{1}$
}

Received: 13 April 2021 / Accepted: 20 June 2021 / Published online: 30 June 2021

(C) Association of Otolaryngologists of India 2021

\begin{abstract}
The tympanic membrane (TM) undergoes a number of pathological changes in middle ear disease which can be detected by a video-otoendoscope. Middle ear disease is also accompanied by changes in middle ear pressure which can be assessed by tympanometry. The objectives of this study were to find the correlation between video-otoendoscopy and tympanometry in acute middle ear infections and to deduce which of the two is more efficient and reliable for early diagnosis. 75 patients with AOM or OME were included over 1 year where each patient was followed for 21 days. Detailed history and clinical examination with videootoendoscope and tympanometry was done on each visit. Each TM was graded using OMGRADE scale. Symptoms and clinical findings consistent with acute otitis media were given a clinical score (CO Score). The results were collected and correlation between video-otoendoscopy and tympanometry was determined and their individual sensitivity, specificity and diagnostic accuracy was calculated. The sensitivity, specificity and diagnostic accuracy for tympanometry and video-otoendoscopy was calculated individually for each of the 4 visits and positive correlation between the 2 was found. Our study showed that tympanometry had a higher overall sensitivity than video-otoendoscopy. While, videootoendoscopy showed a higher specificity than Tympanometry. Otoendoscopy is good for ruling out AOM/OME but cannot rule out persisting Middle Ear Effusion and Tympanometry is a better tool for detecting MEE but cannot differentiate well between AOM and OME. We
\end{abstract}

Ridhima Malik

ridhimamalik93@gmail.com

1 Department of ENT and HNS, SRN Hospital, Prayagraj, Uttar Pradesh, India found that tympanometry plus otoendoscopy together greatly increase the chances of detecting AOM and OME thus improving diagnostic accuracy, reducing financial costs associated with over or mis-diagnosis.

Keywords Acute Otitis Media - Tympanometry · OM grade · Video-otoendoscopy ·

Otitis Media with effusion

\section{Introduction}

Acute Otitis Media (AOM) is a common ailment and a prominent cause of health care visits and antibiotic prescription. Otitis Media with effusion (OME) may occur spontaneously because of poor Eustachian tube function or as an inflammatory response following AOM. Early diagnosis of acute middle ear infection is important for early initiation of treatment and thus preventing future complications and cost implications.

Visualization of the tympanic membrane with identification of the presence of an middle ear effusion (MEE) and inflammatory changes is necessary to establish diagnosis of AOM or OME with certainty. Tympanometry provides a general view of the pressure condition in the middle ear and when the presence of middle ear fluid is difficult to determine, tympanometry can be helpful.

Video-otoendscopy uses endoscopic technology to project the image of the tympanic membrane (TM) onto a monitor visible to both the physician and the patient. It produces a larger, clearer, well-focused image of the TM which allows for analysis of the image any time after image acquisition. This allows for better monitoring the progression of the disease process. 
In AOM, the characteristics of TM and MEE are different than those in OME and these may not be easily distinguishable.

A type B tympanogram with flat curve and normal canal volume is considered diagnostic of OME. Compared with all other types of tympanograms it has a high sensitivity and specificity in detecting OME confirmed surgically [1].

\section{Methods}

This prospective study was conducted in a tertiary health care centre in North India from September 2019 to 2020. 75 patients were examined who were selected from the population visiting the ENT Outpatient Department. Patients included were between the age of 5-18 years, with signs (redness, bulging of TM) and symptoms (fever, tugging, irritability or pain) corresponding with $\mathrm{AOM}$ or OME without any complications and no history of ear trauma or ear surgery. Detailed clinical history was taken and examination was done using video-otoendoscopy followed by tympanometry.

Each patient found having AOM or OME was put on a treatment of Amoxycillin + clavulanic acid along with an antihistaminic, analgesic and nasal decongestant for 1 week. Patients were followed up after 3 days of the 1 st visit and then weekly for 2 weeks. Every patient underwent video-otoendoscopy using Karl Storz Telepack $0^{\circ}$ endoscope and the images were graded on the basis of an imagebased grading scale developed by Lundberg et al. [2] known as the OMGRADE scale, tympanometry was done using Impedance Audiometer GSI Tympanostar Pro and the tympanograms were classified into 5 types according to the modification given by Jerger, with Feldman [3] and was given a clinical score based on the Clinical Score developed by Dagan et al. [4] on each visit. It included categories of fever, irritability, tugging, redness and bulging were classified as absent, mild, moderate or severe. If the eardrum was perforated at the time of the second visit and pus was draining, this was scored by definition as "severe bulging." Maximum score was 15 while minimum score was 0 (Figs. 1, 2).

\begin{tabular}{lll}
\hline Omgrade & $\begin{array}{l}\text { Sub- } \\
\text { division }\end{array}$ & Description \\
\hline 0 & 0 & Transparent TM, normal position \\
1 & $1 \mathrm{R}$ & $\begin{array}{l}\text { Transparent TM, slightly retracted } \\
\text { Transparent TM, normal position, fluid } \\
\text { level or fluid filled ME } \\
\text { Transparent TM, retracted with fluid level } \\
\text { or fluid filled ME }\end{array}$ \\
\hline
\end{tabular}

\begin{tabular}{|c|c|c|}
\hline Omgrade & $\begin{array}{l}\text { Sub- } \\
\text { division }\end{array}$ & Description \\
\hline 2 & $2 \mathrm{OF}$ & $\begin{array}{l}\text { Transparent TM with opaque fluid level, } \\
\text { w/wo retraction }\end{array}$ \\
\hline 3 & 3 & $\begin{array}{l}\text { Opaque appearance of } \mathrm{TM} \text { in a fairly } \\
\text { normal position }\end{array}$ \\
\hline 4 & 4 & Opaque appearance of TM and bulging \\
\hline \multirow[t]{2}{*}{5} & $5 \mathrm{~B}$ & $\begin{array}{l}\text { Opaque appearance of TM with bullous } \\
\text { formations }\end{array}$ \\
\hline & $5 \mathrm{C}$ & $\begin{array}{l}\text { Contourless TM with a wet appearance and } \\
\text { swollen keratin patches, w/wo pulsating } \\
\text { pus from small perforation }\end{array}$ \\
\hline $\begin{array}{l}\text { Temporary } \\
\text { subgrade } 6\end{array}$ & 6 & $\begin{array}{l}\text { TM perforation, retraction pocket or } \\
\text { cholesteatoma w/wo purulent discharge, } \\
\text { previous ear surgery and TM grommets }\end{array}$ \\
\hline
\end{tabular}

\section{Results}

A total of 75 patients ( 22 females, 53 males) were included in this study aged between 5 and 18 years. 4 out of these 75 patients were lost to follow-up. The mean age was $13.65 \pm 3.59$ years. Each patient who had signs and symptoms of AOM or OME and were given a $\mathrm{CO}$ score.

Irritability was present in majority of patients (98.67\%) on the 1st visit followed by redness $(93.33 \%)$. On the 2 nd visit redness was present in majority of patients (72.22\%) followed by tugging $(62.50 \%)$. Tugging was present in majority $(38.03 \%)$ of patients on 3rd visit followed by redness $(22.54 \%)$. On the 4 th visit Tugging was present in $8.45 \%$ patients while none had fever, irritability, redness and bulging (Table 1).

Moderate agreement exists between tympanogrmas and video-otoendoscopy on each visit with kappa value 0.472 on the 1 st, 0.452 on the $2 \mathrm{nd}, 0.380$ on the $3 \mathrm{rd}$ and 0.516 on the 4th visit. Significant correlation was seen in the distribution of tympanongrams and video-otoendoscopic images on each visit $(p$ value $<0.5)$ (Table 4$)$.

Tympanogram at 1 st visit was A in $50 \%$ of patients in $1 \mathrm{R}, 0 \%$ of patients in $1 \mathrm{RF}, 0 \%$ of patients in $2 \mathrm{OF}, 0 \%$ of patients in $3,5 \%$ of patients in $4,3.33 \%$ of patients in $5 \mathrm{~B}$ and $0 \%$ of patients in $5 \mathrm{C}$. Tympanogram at 1 st visit was $\mathrm{B}$ in $100 \%$ of patients in $5 \mathrm{C}, 100 \%$ of patients in $2 \mathrm{OF}, 100 \%$ of patients in 3 and $96.67 \%$ of patients in $5 \mathrm{~B}, 50 \%$ of patients in $1 \mathrm{R}, 92.86 \%$ of patients in $1 \mathrm{RF}$ and $95 \%$ of patients in 4. Tympanogram at 1 st visit was $\mathrm{C}$ in $7.14 \%$ of patients in $1 \mathrm{RF}, 0 \%$ of patients in $1 \mathrm{R}, 0 \%$ of patients in 2OF, $0 \%$ of patients in 3, $0 \%$ of patients in $4,0 \%$ of patients in $5 \mathrm{~B}$ and $0 \%$ of patients in $5 \mathrm{C}$ (Fig. 3). 

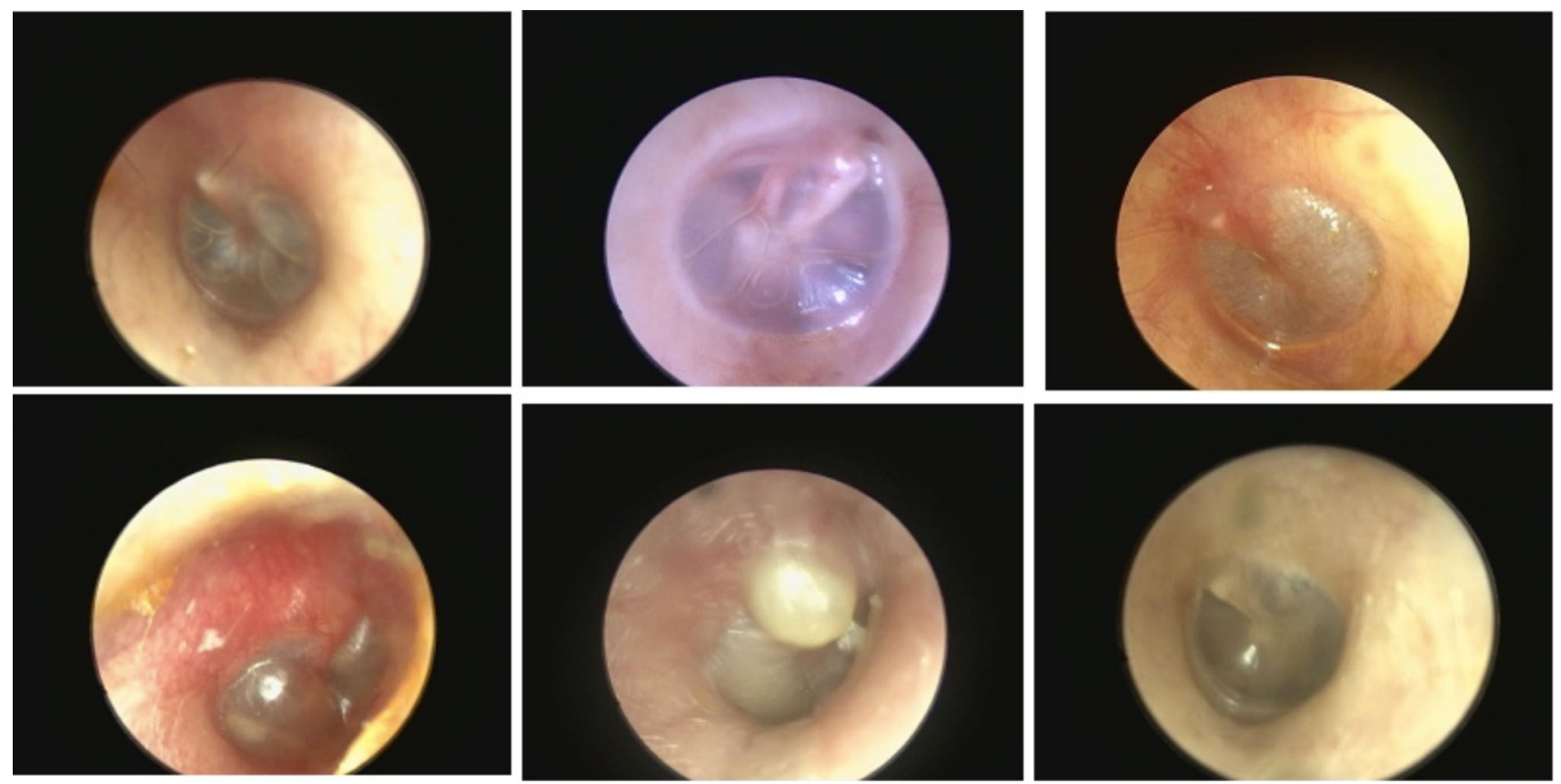

Fig. 1 OM Grade of video-otoendoscopic images. Upper row left to right Grade 2OF, Grade 1RF, Grade 4. Lower row left to right: Grade 5B, Grade 5B, Grade 0

Tympanogram at 2 nd visit was A in $42.11 \%$ of patients in $1 \mathrm{R}, 6.90 \%$ of patients in $1 \mathrm{RF}, 0 \%$ of patients in $2 \mathrm{OF}, 0 \%$ of patients in $3,0 \%$ of patients in $4,0 \%$ of patients in $5 \mathrm{~B}$ and $0 \%$ of patients in $5 \mathrm{C}$. Tympanogram at 2 nd visit was $\mathrm{B}$ in $100 \%$ of patients in $5 \mathrm{C}, 100 \%$ of patients in $2 \mathrm{OF}, 100 \%$ of patients in 3,100\% of patients in 4 and $100 \%$ of patients in $5 \mathrm{~B}$ and $93.10 \%$ of patients in $1 \mathrm{RF}, 52.63 \%$ of patients in $1 \mathrm{R}$. Tympanogram at 2 nd visit was $\mathrm{C}$ in $5.26 \%$ of patients in $1 \mathrm{R}$.

Tympanogram at $3 \mathrm{rd}$ visit was A in $100 \%$ of patients in $0,58.82 \%$ of patients in $1 \mathrm{R}, 0 \%$ of patients in $1 \mathrm{RF}, 0 \%$ of patients in 3 and $0 \%$ of patients in 4 . Tympanogram at $3 \mathrm{rd}$ visit was B in $100 \%$ of patients in $4,100 \%$ of patients in $1 \mathrm{RF}$ and $100 \%$ of patients in 3,0\% of patients in 0 and $39.22 \%$ of patients in $1 \mathrm{R}$. Tympanogram at 3rd visit was $\mathrm{C}$ in $1.96 \%$ of patients in $1 \mathrm{R}$.

Tympanogram at 4 th visit was A in $100 \%$ of patients in $0,54.55 \%$ of patients in $1 \mathrm{R}, 0 \%$ of patients in $1 \mathrm{RF}$ and $0 \%$ of patients in 4. Tympanogram at 4th visit was B in $100 \%$ of patients in 4 and $100 \%$ of patients in $1 \mathrm{RF}, 0 \%$ of patients in 0 and $45.45 \%$ of patients in $1 \mathrm{R}$.

Univariate logistic regression was performed taking OM grade at 1 st visit as independent variable to predict tympanogram finding at 2nd visit, 3rd visit and 4th visit. Patients categorized as diseased by OM grade at 1 st visit had significantly higher chances of tympanogram $\mathrm{B} / \mathrm{C}$ at 2nd visit with odds ratio of 19.139 . No significant relation was seen between OM grade at 1st visit and tympanogram finding at 3 rd visit and 4 th visit ( $\mathrm{p}$ value $>0.05$ ). On taking tympanogram at 1 st visit as independent variable to predict OM grade finding at 2 nd visit, 3 rd visit and 4 th visit. No significant relation was seen between tympanogram at $1 \mathrm{st}$ visit and $\mathrm{OM}$ grade at 2 nd visit, 3rd visit and 4th visit $(p$ value $>0.05)$ (Table 5).

\section{Discussion}

We used both tympanometry as well as video-otoendoscopy to the assess the tympanic membrane and the condition of the middle ear and used a Clinical Score for diagnosing AOM or OME as standard.

Pain /irritability was the most common presenting complaint followed by tugging and fever. This correlated well with studies performed by Niemela et al. and Rothman et al. $[5,6]$ according to whom earache was present in majority of the patients of AOM and also the most useful symptom for diagnosis. The most common sign among the patients was redness of the TM followed by bulging of the TM. However Karma et al. and McCormick et al. [7, 8] found bulging of the TM had higher specificity (97\%) while redness of the TM only correlated with the presence of AOM.

In our study TM's were graded on the basis of OM Grade using an otoendoscope which showed a sensitivity of $94.67 \%$ and PPV $100 \%$ on the 1 st visit. A sensitivity of $92.31 \%$,specificity of $48.48 \%$, PPV $67.92 \%$ and NPV $84.21 \%$ on the 2 nd visit. On the 3 rd visit we found 


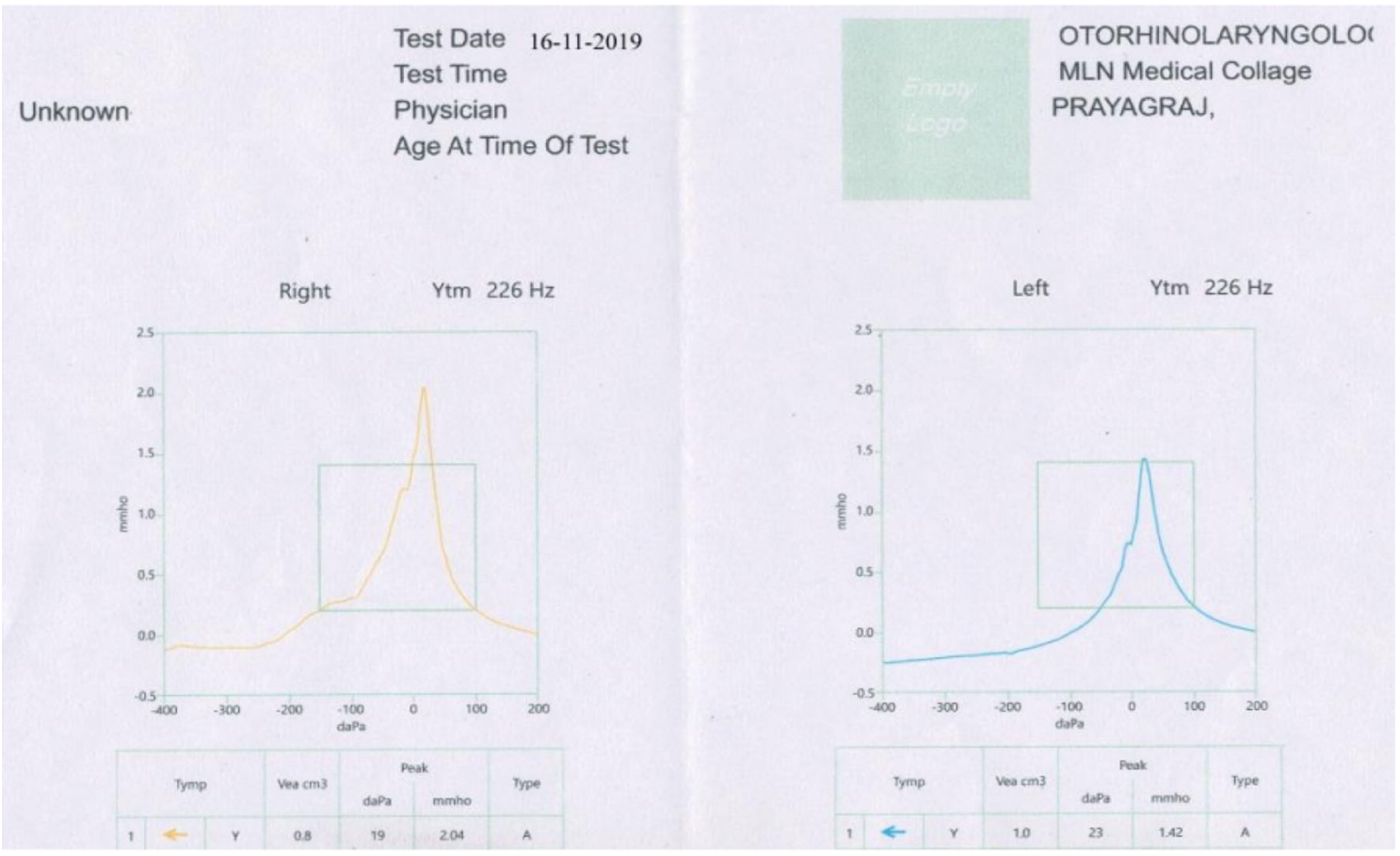

Test Date 12-03-20

OTORHINOLARYNGOLO

Test Time

MLN Medical Collage

Physician

PRAYAGRAJ,

Age At Time Of Test
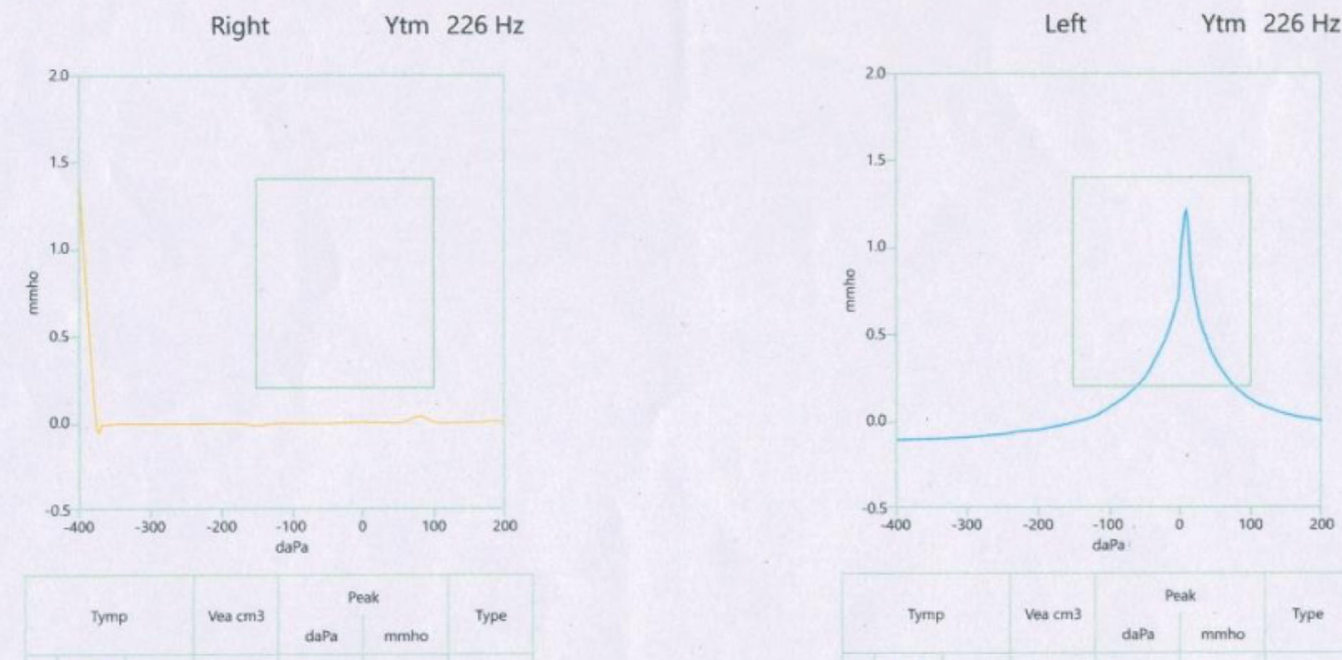

Fig. 2 Tympanograms upper: right-type A, left-type A; lower: right-type B, left-Type A

sensitivity of $66.67 \%$,specificity of $85.29 \%$, PPV $16.67 \%$ and NPV 98.31\%. On the 4th visit we found that OM grade had a specificity of $95.77 \%$ and a NPV of $100 \%$ (Table 2). Our findings correlated well with a study by Takata et al. [9] who found that the sensitivity of pneumatic otoscopy was $94 \%$, Lee and Yeo [10] who found that the sensitivity of pneumatic otoscopy was $97.2 \%$ and a specificity $38 \%$ while poor correlation was found with a study by Rogers et al. [11] who found that pneumatic otoscopy had a sensitivity of $67.9 \%$, specificity of $81.4 \%$ while Binocular microscopy performed by staff paediatric otolaryngologist 
Table 1 Distribution of frequency (percentage) of signs/symptoms of study subjects

\begin{tabular}{llcccc}
\hline & Fever & Irritability/pain & Tugging & Redness & Bulging \\
\hline 1st visit $(\mathrm{n}=75)$ & $42(56.00 \%)$ & $74(98.67 \%)$ & $57(76.00 \%)$ & $70(93.33 \%)$ & $60(80.00 \%)$ \\
2nd visit $(\mathrm{n}=72)$ & $3(4.17 \%)$ & $39(54.17 \%)$ & $45(62.50 \%)$ & $52(72.22 \%)$ & $35(48.61 \%)$ \\
3rd visit $(\mathrm{n}=71)$ & $0(0.00 \%)$ & $10(14.08 \%)$ & $27(38.03 \%)$ & $16(22.54 \%)$ & $2(2.82 \%)$ \\
4th visit $(\mathrm{n}=71)$ & $0(0.00 \%)$ & $0(0.00 \%)$ & $6(8.45 \%)$ & $0(0.00 \%)$ & $0(0.00 \%)$ \\
\hline
\end{tabular}

Association of tympanogram at 1st visit with $O M$ grade at 1 st visit

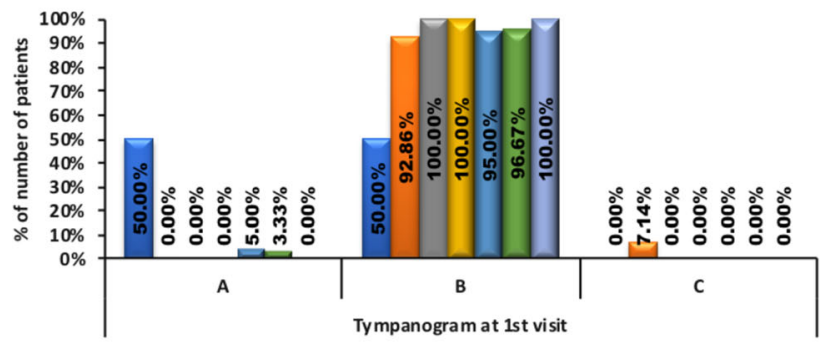

$\square 1 R(n=4) \square 1 R F(n=14) \quad \square 2 O F(n=4) \quad \square 3(n=2) \quad \square 4(n=20) \quad \square 5 B(n=30) \quad \square 5 C(n=1)$
Association of tympanogram at 2 nd visit with $O M$ grade at 2 nd visit

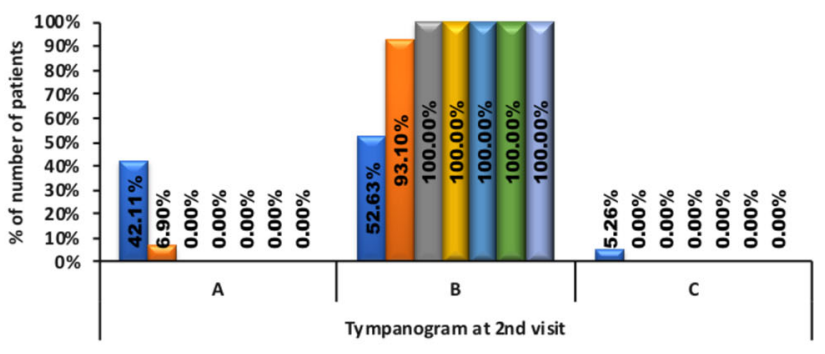

$\square 1 R(n=19) \square 1 R F(n=29) \square 2 O F(n=4) \square 3(n=1) \square 4(n=15) \square 5 B(n=1) \square 5 C(n=3)$
Association of tympanogram at 3 rd visit with OM grade at 3 rd visit

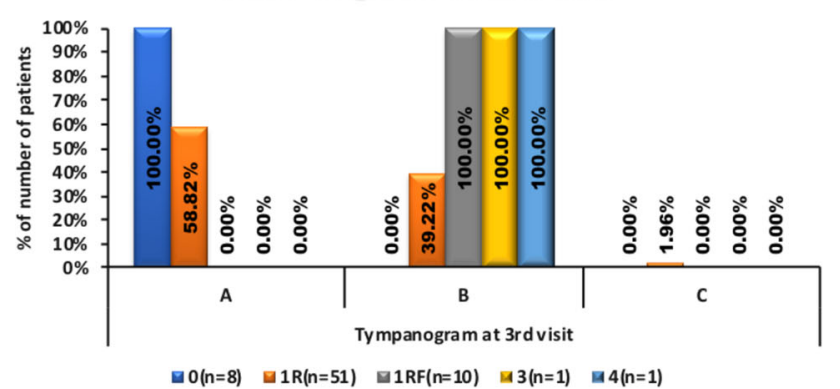

Association of tympanogram at 4 th visit with $O M$ grade at 4 th visit

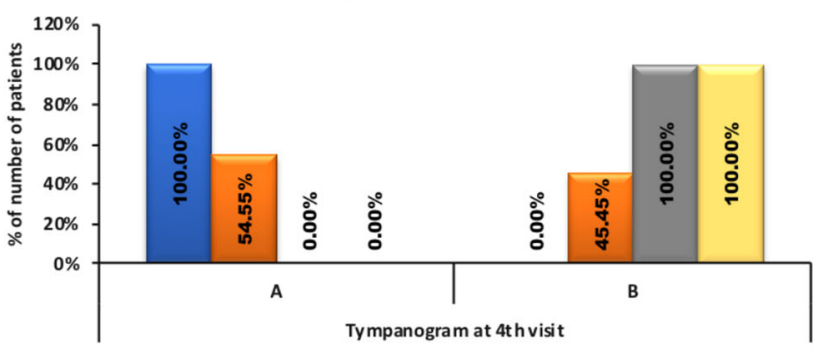

$\square 0(n=57) \quad \square 1 R(n=11) \quad \square 1 R F(n=2) \quad \forall 4(n=1)$

Fig. 3 Association of tympanogram on various visits with OM Grade

Table 2 Sensitivity, specificity, NPV, PPV and diagnostic accuracy of OM grade taking CO score as standard

\begin{tabular}{|c|c|c|c|c|c|}
\hline & \multicolumn{5}{|l|}{ OM grade } \\
\hline & Sensitvity & Specificity & NPV & PPV & $\begin{array}{l}\text { Diagnostic } \\
\text { accuracy }\end{array}$ \\
\hline 1st visit $(\mathrm{n}=75)$ & $\begin{array}{l}94.67 \% \\
\quad(86.90-98.53 \%)\end{array}$ & - & - & $100 \%(94.94-100.00 \%)$ & - \\
\hline $2 \mathrm{nd}$ visit $(\mathrm{n}=72)$ & $\begin{array}{l}92.31 \% \\
\quad(79.13-98.38 \%)\end{array}$ & $48.48 \%(30.80-66.46 \%)$ & $84.21 \%(60.42-96.62 \%)$ & $\begin{array}{l}67.92 \% \\
\quad(53.68-80.08 \%)\end{array}$ & $72.22 \%$ \\
\hline 3rd visit $(n=71)$ & $66.67 \%(9.43-99.16 \%)$ & $\begin{array}{l}85.29 \% . \\
\quad(74.61-92.72 \%)\end{array}$ & $98.31 \%(90.91-99.96 \%)$ & $16.67 \%(2.09-48.41 \%)$ & $84.51 \%$ \\
\hline 4 th visit $(n=71)$ & - & $\begin{array}{l}95.77 \% . \\
\quad(88.14-99.12 \%)\end{array}$ & $\begin{array}{l}100.00 \% \\
\quad(94.72-100.00 \%)\end{array}$ & - & - \\
\hline
\end{tabular}


Table 3 Sensitivity, specificity, NPV, PPV and diagnostic accuracy of tympanometry taking CO score as standard

\begin{tabular}{|c|c|c|c|c|c|}
\hline & \multicolumn{5}{|l|}{ Tympanometry } \\
\hline & Sensitvity & Specificity & NPV & PPV & $\begin{array}{l}\text { Diagnostic } \\
\text { Accuracy }\end{array}$ \\
\hline 1 st visit $(\mathrm{n}=75)$ & $94.67 \%(86.90-98.53 \%)$ & - & - & $\begin{array}{l}100 \% \\
\quad(94.94-100.00 \%)\end{array}$ & - \\
\hline 2nd visit $(\mathrm{n}=72)$ & $97.44 \%(86.52-99.94 \%)$ & $\begin{array}{l}27.27 \% \\
\quad(13.30-45.52 \%)\end{array}$ & $90.00 \%(55.50-99.75 \%)$ & $\begin{array}{l}61.29 \% \\
\quad(48.07-73.40 \%)\end{array}$ & $65.28 \%$ \\
\hline 3rd visit $(n=71)$ & $\begin{array}{l}100.00 \% \\
\quad(29.24-100.0 \%)\end{array}$ & $\begin{array}{l}55.88 \% \\
\quad(43.32-67.92 \%)\end{array}$ & $\begin{array}{l}100.00 \% \\
\quad(90.75-100.00 \%)\end{array}$ & $9.09 \%(1.92-24.33 \%)$ & $57.75 \%$ \\
\hline 4 th visit $(n=71)$ & - & $88.73 \%(79.0-95.01 \%)$ & $\begin{array}{l}100.00 \% \\
\quad(94.31-100.00 \%)\end{array}$ & - & - \\
\hline
\end{tabular}

Table 4 Correlation of tympanogram with video-otoendoscopy (OM grade) at each visit

\begin{tabular}{|c|c|c|c|c|}
\hline \multirow[t]{2}{*}{ Tympanogram at 1 st visit } & \multicolumn{2}{|c|}{ OM grade at 1 st visit } & \multirow[t]{2}{*}{$P$ value } & \multirow[t]{2}{*}{ Kappa } \\
\hline & $\operatorname{Normal}(\mathrm{n}=4)$ & Disease $(\mathrm{n}=71)$ & & \\
\hline Normal & $2(50 \%)$ & $2(2.82 \%)$ & 0.013 & 0.472 \\
\hline Disease & $2(50 \%)$ & $69(97.18 \%)$ & & \\
\hline \multirow[t]{2}{*}{ Tympanogram at 2 nd visit } & \multicolumn{2}{|c|}{ OM grade at 2 nd visit } & $P$ value & Kappa \\
\hline & Normal (n = 19) & Disease $(\mathrm{n}=53)$ & & \\
\hline Normal & $8(42.11 \%)$ & $2(3.77 \%)$ & 0.0002 & 0.452 \\
\hline Disease & $11(57.89 \%)$ & $51(96.23 \%)$ & & \\
\hline \multirow[t]{2}{*}{ Tympanogram at 3 rd visit } & \multicolumn{2}{|c|}{ OM grade at 3 rd visit } & $P$ value & Kappa \\
\hline & Normal $(\mathrm{n}=59)$ & Disease $(n=12)$ & & \\
\hline Normal & $38(64.41 \%)$ & $0(0 \%)$ & $<.0001$ & 0.380 \\
\hline Disease & $21(35.59 \%)$ & $12(100 \%)$ & & \\
\hline \multirow[t]{2}{*}{ Tympanogram at 4 th visit } & \multicolumn{2}{|c|}{ OM grade at 4 th visit } & $P$ value & Kappa \\
\hline & Normal $(\mathrm{n}=68)$ & Disease $(\mathrm{n}=3)$ & & \\
\hline Normal & $63(92.65 \%)$ & $0(0 \%)$ & 0.001 & 0.516 \\
\hline Disease & $5(7.35 \%)$ & $3(100 \%)$ & & \\
\hline
\end{tabular}

showed the best sensitivity, $88.0 \%$, and best specificity, $89 \%$.

We found that Tympanogram was type B in $93.33 \%$ of patients in first visit and type $\mathrm{A}$ in $5.33 \%$ of patients in first visit. This correlated well with the study done by Groothius et al. [12] who found that at the time of diagnosis of AOM, $87 \%$ of tympanograms were type B.

Renko et al. [13] found normal tympanograms after a median time of 7.5 days (range 1-58 days) among 75 successfully monitored patients. This correlated well with our study where we found normal tympanograms in
$53.52 \%$ patients after 10 days and in $88.73 \%$ patients after 17-21 days.

We found tympanometry to have a sensitivity of $94.67 \%$ and PPV $100 \%$ on the 1 st visit. Tympanometry had a sensitivity of $97.44 \%$, specificity of $27.27 \%$, PPV $61.29 \%$, NPV $90 \%$ on the 2nd visit and a sensitivity of $100 \%$, specificity of $55.88 \%$, PPV $9.09 \%$, NPV $100 \%$ on the 3 rd visit. While,the specificity on the 4 th visit was $88.73 \%$ along with NPV 100\% (Tables 3, 4).

The tympanic membranes categorized as diseased by OM grade at 1 st visit had significantly higher chances of tympanogram B/C at 2nd visit (Table 5). 
Table 5 Univariate logistic regression to find out the relationship of OM grade at 1st visit with findings of tympanogram at 2nd visit, 3rd visit and 4th visit and the relationship of tympanogram at 1st visit with findings of OM grade at 2nd visit, 3rd visit and 4th visit

\begin{tabular}{|c|c|c|}
\hline Variable & $P$ value & Odds ratio \\
\hline \multicolumn{3}{|c|}{ OM grade at 1 st visit with findings of tympanogram at 2 nd visit } \\
\hline Normal & & 1.000 \\
\hline Diseased & 0.011 & 19.139 \\
\hline \multicolumn{3}{|c|}{ OM grade at 1 st visit with findings of tympanogram at $3 \mathrm{rd}$ visit } \\
\hline Normal & & 1.000 \\
\hline Diseased & 0.497 & 2.136 \\
\hline \multicolumn{3}{|c|}{ OM grade at 1st visit with findings of tympanogram at 4th visit } \\
\hline Normal & & 1.000 \\
\hline Diseased & 0.883 & 1.286 \\
\hline \multicolumn{3}{|c|}{ Tympanogram at 1st visit with findings of OM grade at 2 nd visit } \\
\hline Type A & & 1.000 \\
\hline Type B & 0.298 & 2.943 \\
\hline \multicolumn{3}{|c|}{ Tympanogram at 1st visit with findings of OM grade at $3 \mathrm{rd}$ visit } \\
\hline Type A & & 1.000 \\
\hline Type B & 0.677 & 2.027 \\
\hline \multicolumn{3}{|c|}{ Tympanogram at 1st visit with findings of OM grade at 4th visit } \\
\hline Type A & & 1.000 \\
\hline Type B & 0.683 & 0.488 \\
\hline
\end{tabular}

According to the $\mathrm{p}$ values we can draw the conclusion that changes due to AOM or OME in tympanometry as well as video-otoendoscopy are most evident on the 1 st and 2nd visit.

This implies that otoendoscopy detects AOM/OME before tympanometry and can therefore diagnose it earlier. Thus, if there is an abnormal otoendoscopic image on the 1 st visit then there are high chances that the tympanogram obtained on the next visit will be abnormal as well. Whereas, a normal tympanogram could not completely rule out the presence of effusion.

Our findings correlate well with the studies done by Bluestone, Beery and Paradise [14] who found that in 59 ears with type B tympanograms effusions were found in 49 ears $(83 \%)$, Fiellau-Nikolajsen et al. [15] who found a nearly $100 \%$ correlation between a flat tympanogram and the presence of MEE as well as Groothuis et al. [12] who found that Type A tympanograms correlated well with normal otoscopic findings in $92 \%$ cases and Type B tympanograms were associated with abnormal otoscopic findings in $93 \%$ of cases. Smith et al. [16] found MEE in $80.2 \%$ patients with Type B tympanograms. Helenius et al. [17] found that Flat (type B) tympanogram was related to otitis media with effusion in $44 \%$ and to acute otitis media in $56 \%$ of examinations, respectively.

We found that tympanometry had a higher overall Sensitivity than video- otoendoscopy. While, videootoendoscopy showed a higher specificity than
Tympanometry. Thus, tympanometry is good for catching actual cases of OME but it also comes with a fairly high rate of false positives. Whereas, Otoendoscopy is superior at early diagnosis of AOM/OME but cannot rule out persisting MEE. This shows that while tympanometry is a good tool for detecting residual or persisting MEE but it cannot differentiate between AOM and OME. Also, tympanometry alone cannot determine the presence or absence of acute middle ear infections.

\section{Conclusion}

Our study found that there is good correlation between tympanometry and video-otoendoscopy. Otoendoscopy remains superior to tympanometry in detecting AOM. On the other hand, tympanometry is more precise in detecting the presence or absence of MEE.

It also shows that tympanometry plus otoendoscopy together greatly increase the chances of detecting AOM and OME. Using both these modalities together:

1. Reduces overdiagnosis and unnecessary treatment. Increases the probability of correct diagnosis of other conditions with symptoms that otherwise could be attributed to AOM.

2. Improve diagnostic accuracy

3. Reduces financial costs associated with misdiagnosis

4. Promote consistency in diagnosis 
5. Helps in monitoring and documentation of the progression of the disease process for patients being considered for surgical treatment.

Thus we can conclude that instead of using only otoscopy for diagnosing AOM or OME, we should utilize both otoendoscopy as well as tympanometry at the first visit itself for early diagnosis of AOM and early detection of MEE before development of any sequalae which can be missed if these modalities are not used.

Our study had certain limitations such as a small sample size because of the limited OPD operations due to COVID19 pandemic as well as a higher faith in alternative medicine which leads to several drop-outs.

\section{Declarations}

Conflict of interest There are no conflicts of interest.

Ethical Approval The study was approved by the Institutional Ethics Committee.

\section{References}

1. Johansen EC, Lildholdt T, Damsbo N, Eriksen EW (2000) Tympanometry for diagnosis and treatment of otitis media in general practice. Fam Pract 17(4):317-322

2. Lundberg T, Biagio L, Laurent C, Sandström H, Swanepoel DW (2014) Remote evaluation of video-otoscopy recordings in an unselected pediatric population with an otitis media scale. Int $\mathbf{J}$ Pediatr Otorhinolaryngol 78(9):1489-1495

3. Feldman AS (1976) Tympanometry: application and interpretation. Ann Otol Rhinol Laryngol 85:202-208

4. Dagan R D, Leibovitz E, Greenberg D (1998) Early eradication of pathogens from middle ear fluid during antibiotic treatment of acute otitis media is associated with improved clinical outcome. Pediatr Infect Dis J

5. Niemela M, Uhari M, Jounio-Ervasti K, Luotonen J, Alho OP, Vierimaa E (1994) Lack of specific symptomatology in children with acute otitis media. Pediatr Infect Dis J 13(9):765-768

6. Rothman R, Owens T, Simel DL (2003) Does this child have acute otitis media? JAMA 290(12):1633-1640
7. Karma PH, Penttilä MA, Sipilä MM (1989) Otoscopic diagnosis of middle ear effusion in acute and non-acute otitis media. I. The value of different otoscopic findings. Int J Pediatric Otorhinolaryngol 17(1):37-49

8. McCormick DP, Elizabeth L-M, Kokab S (2000) Otitis media: can clinical findings predict bacterial or viral etiology? Pediatric Infect Dis J 19(3):256-258

9. Takata GS, Chan LS, Morphew T, Mangione-Smith R, Morton SC, Shekelle P (2003) Evidence assessment of the accuracy of methods of diagnosing middle ear effusion in children with otitis media with effusion. Pediatrics 112(6 Pt 1):1379-1387

10. Lee D-H, Yeo S-W (2004) Clinical diagnostic accuracy of otitis media with effusion in children, and significance of myringotomy: diagnostic or therapeutic? J Korean Med Sci 19(5):739-743

11. Rogers DJ, Boseley ME, Adams MT, Makowski RL, Hohman MH (2010) Prospective comparison of handheld pneumatic otoscopy, binocular microscopy, and tympanometry in identifying middle ear effusions in children. Int J Pediatr Otorhinolaryngol 74(10): 1140-1143

12. Groothuis JR, Sell SH, Wright PF, Thompson JM, Altemeier WA (1979) Otitis media in infancy: tympanometric findings. Pediatrics 63(3):435-442

13. Renko M, Kontiokari T, Jounio-Ervasti K, Rantala H, Uhari M (2006) Disappearance of middle ear effusion in acute otitis media monitored daily with tympanometry. Acta Paediatr 95(3):359-363

14. Bluestone CD, Beery QC, Paradise JL (1973) Audiometry and tympanometry in relation to middle ear effusions in children. Laryngoscope 83(4):594-604

15. Fiellau-Nikolajsen M (1983) Tympanometric prediction of the magnitude of hearing loss in preschool-children with secretory otitis media. Scand Audiol Suppl 17:68-72

16. Smith CG, Paradise JL, Sabo DL, Rockette HE, Kurs-Lasky M, Bernard BS et al (2006) Tympanometric findings and the probability of middle-ear effusion in 3686 infants and young children. Pediatrics 118(1):1-13

17. Helenius KK, Laine MK, Tähtinen PA, Lahti E, Ruohola A (2012) Tympanometry for discrimination of otoscopic diagnoses in young ambulatory children. Pediatric Infect Dis J 31(10):1003-1006

Publisher's Note Springer Nature remains neutral with regard to jurisdictional claims in published maps and institutional affiliations. 